\title{
Issues of management of Epidermolysis bullosa in Georgia
}

\author{
Oleg Kvlividze ${ }^{1 *}$, Tamar Chigladze², George Tvaliashvili, George Galdava ${ }^{3}$ \\ From 5th European Conference on Rare Diseases (ECRD 2010) \\ Krakow, Poland. 13-15 May 2010
}

As of today there are no radical methods of treatment of epidermolysis bullosa (EB) as well as other genetically determined diseases. This accounts for the acuteness of the problem of providing adequate care for such patients.

The Georgian Foundation for Genetic and Rare Diseases (GeRaD), a self-help organisation of people personally affected by rare diseases in Georgia, observed 3 patients, age $1.5,2$, and 3.5 years. The first 2 patients were diagnosed with dystrophic polydysplastic form of $E B$, while the third one had a simple generalised epydermolytic form. All patients were received in various clinics and with various level of success some pathogenetic (steroids, erythromycin, tocopherol acetate, retinoids), symptomatic, and local treatment. All of them had reached periods of remission of various lengths. It should be noted that the longest remission was achieved, contrary to the opinion of many authoritative dermatologists, as a result of treatment with Phenytoin. The families of the patients, despite notable therapeutic success, faced care and nutrition related problems caused by the lack of information about the disease that affected their children. We tried to solve these problems by addressing the Institute of Dermatology and Venereology. During 6 months in the frame of the activities of the nursing for patients with severe dermatoses the doctors and nurses of the Institute provided free treatment for our patients and information for their parents about actual issues of living with EB (care, nutrition, prevention of opportunistic infections, etc.). According to the parents' evaluations, the quality of life of their children significantly improved due to our activities. This example of successful collaboration between a State medical

\footnotetext{
*Correspondence: grd.georgia@gmail.com

${ }^{1}$ Research Project, Georgian Foundation for Genetic and Rare Diseases, 81

Abashidze Street, 0162 Tbilisi, Georgia

Full list of author information is available at the end of the article
}

institution and an NGO in the sphere of providing care for patients with rare diseases may serve as one of the preconditions for creation of the optimal model of management of rare diseases in Georgia.

\section{Author details}

${ }^{1}$ Research Project, Georgian Foundation for Genetic and Rare Diseases, 81 Abashidze Street, 0162 Tbilisi, Georgia. ${ }^{2}$ Georgian Foundation for Genetic and Rare Diseases, 81 Abashidze Str., 0162 Tbilisi, Georgia. ${ }^{3}$ Dermatology and Venereology Research Institute, 55 Ninoshvili St, Tbilisi, Georgia.

Published: 19 October 2010

doi:10.1186/1750-1172-5-S1-P28

Cite this article as: Kvlividze et al:: Issues of management of

Epidermolysis bullosa in Georgia. Orphanet Journal of Rare Diseases 2010 5(Suppl 1):P28.
Submit your next manuscript to BioMed Central and take full advantage of:

- Convenient online submission

- Thorough peer review

- No space constraints or color figure charges

- Immediate publication on acceptance

- Inclusion in PubMed, CAS, Scopus and Google Scholar

- Research which is freely available for redistribution

Submit your manuscript at www.biomedcentral.com/submit
Biomed Central 